\title{
Globalização e estratégias locais: as interações global-local no caso do município de Mocajuba, na Amazônia oriental
}

\section{Globalization and local strategies: the global-local interactions in the case of the municipality of Mocajuba, in the Eastern Amazon}

Pauline Cuenin - Mestranda de Extensão Rural na Universidade Federal de Viçosa (UFV). E-mail: pauline.cuenin3@gmail.com

Marc Piraux - Doutor em Agro-economia, pela na Faculté des Sciences Agronomiques de Gembloux. Pesquisador e docente da Universidade Federal do Pará (UFPA). E-mail: marc.piraux@cirad.fr

\section{Resumo}

Este artigo objetiva analisar e entender, em um contexto de globalização, as interações entre o local e o global que permitam uma melhor autonomia dos territórios locais. Neste objetivo, estudou-se um território da Amazônia Oriental, considerado rural e isolado, mas integrado nos processos de globalização: Mocajuba-Pa. Uma análise de fluxos dentro do município e entre este e o exterior, assim como dos diferentes projetos de desenvolvimento local foi conduzida. Esta análise mostrou os impactos no local das influências globalizadas, tais como a homogeneização dos modelos de consumo e a fragmentação do território. No entanto, destacouse também iniciativas locais e as suas conexões com o global, enfatizando um local que interage com várias escalas. Essas experiências, baseadas na articulação das diferentes escalas e atores, destacam-se por apresentar potencialidades para uma maior autonomia do território.

\begin{abstract}
This article aims to analyze and understand, in a context of globalization, the interactions between local and global that allow a better autonomy of local territories. In this objective, we studied a territory of Eastern Amazonia, considered rural and isolated, but integrated in the processes of globalization: Mocajuba-Pa. An analysis of flows within the municipality and between this and abroad, as well as the different local development projects was conducted. This analysis showed the local impacts of globalized influences, such as the homogenization of consumption models and the fragmentation of the territory. However, local initiatives and their connections with the global have also been highlighted, emphasizing a locus that interacts with several scales. These experiences, based on the articulation of the different scales and actors, stand out for having potential for greater autonomy of the territory.
\end{abstract}

\section{Palavra-chave}

Globalização. Lugar. Território. Amazônia.

\section{Keywords}

Globalization. Place. Territory. Amazon. 


\section{INTRODUÇÃO}

A globalização tem múltiplas formas, características e significações associadas às compreensões sobre os efeitos sociais e espaciais diferentes. A aceleração, extensão e intensificação dos fluxos, tanto na escala global quanto na escala dos territórios nacionais, demonstram uma nova forma de globalização (BRUNET; DOLLFUS, 1990; DOLLFUS, 1997; DURAND; LÉVY; RETAILLÉ, 1992; HELD, 1999). Diante deste fato, a globalização se torna um processo de intensificação das relações sociais mundiais que integram os territórios e atividades, unindo as localidades distantes e transcendendo os Estados (GIDDENS, 1990; RAINELLI, 2007). A partir desta definição, parece que a globalização oferece oportunidades para todas as regiões e setores do mundo, reduzindo as desigualdades sociais.

No entanto, é sem considerar a "perversidade" da globalização (SANTOS, M., 2000). A partir do consenso econômico neoliberal de Washington de 1989, o poder econômico se concentrou nas mãos das empresas multinacionais. Elas se tornaram atores centrais na economia global. Disto resulta uma forma de subordinação dos Estados que ameaça suas soberanias e reforça o caráter periférico de alguns espaços. Isto significa que a deficiência em capitais, homens, serviços e poder destes espaços em relação aos centros aumenta quando estes são cada vez mais atrativos (REYNAUD, 1981). Baseada na competitividade, a globalização gerou processos de concentração de riqueza, ou seja, processos de exclusão e de produção de desigualdades sociais. Ao nível cultural, os valores, artefatos e símbolos culturais tendem a se uniformizar pela integração progressiva das culturas e pela disseminação da cultura ocidental (SANTOS, B., 2002a).

Diante desse processo de globalização hegemônica, o local se vê integrado no global pela inclusão-exclusão: o local está incluído, mas subordinado à lógica do global, ou está marginalizado e excluído dessa lógica. O lugar, a noção entendida neste trabalho como sendo próxima à de território no sentido de um espaço apropriado (RAFFESTIN, 1986), perdeu sua importância frente a lógica de escala dominante que tornou todas as alternativas locais ocultas e não credíveis. Assim, além da forte dicotomia global/local, a assimetria entre as duas escalas aumenta pela difusão de um discurso hegemônico que favorece a posição dominante do global (SANTOS, B., 2002a, 2002b).

Como enfatiza a ecologia das transescalas de Boaventura de Sousa Santos (2002b), parece necessário revalorizar o lugar e as suas experiências e, mais do que isso, rearticular o lugar e o global para considerar a diversidade das alternativas e, a partir disso, repensar a globalização saindo da visão 
dominante. De fato, como se pode acreditar por um pensamento determinista, a globalização não é espontânea, automática e irreversível, mas é evolutiva e multiforme. De fato, diferentes formas de globalização existem dentro das quais podem destacar formas de globalizações contra hegemônicas mais humanas, que se baseiam nas iniciativas locais e nas ligações transnacionais e translocais, ou seja, o cruzamento de lutas locais de resistência contra às trocas desiguais provocadas pela globalização hegemônica que é geralmente materializado em redes em escalas maiores (SANTOS, B., 2002a). O lugar, as suas experiências e os seus conhecimentos por si só não podem resolver todos os problemas e não podem se tornar outra forma de hegemonia. Para isso, repensar a noção do lugar é apontado como essencial (ESCOBAR, 2005).

O lugar tem especificidade, mas não pode ser visto como estático, com fronteiras demarcadas e identidades únicas, e preso em uma história longa e internalizada. Ao contrário, o lugar é um espaço vivido, de experiência sempre renovada que compreende o espaço físico, as interações internas e as interações com os outros lugares: ele é o intermediário entre o mundo e o indivíduo. As estritas conexões lugar-cultura ou lugar-povo foram rompidas para dar emergência ao cosmopolitismo. O lugar deve ser concebido, então, em um sentido extravertido enfatizando as suas relações com o mundo, como um lócus particular de entrelaço de relações sociais e de encontro (ESCOBAR, 2005; MASSEY, 2000; MONTERO, 1997; SANTOS, M., 2000, 2008), o que remete a noção de lugar à de território segundo Raffestin (1986).

Assim definido, é possível pensar nos processos de localização ou de relocalização na simultaneidade dos processos de globalização, e no processo de desglobalização do local acompanhado de uma eventual reglobalização contra hegemônica. De fato, os dois processos de globalização e localização não podem ser vistos separadamente, a globalização pressupondo a localização (SANTOS, B., 2002a, 2002b).

Neste artigo, então, tencionamos entender como ocorre esses processos em territórios aparentemente subordinados às lógicas da globalização hegemônica. Este artigo objetiva entender e analisar as interações entre o local e o global e identificar as iniciativas locais que permitam uma melhor autonomia dos territórios locais. Especificamente, objetiva identificar os fatores chaves que permitam reforçá-las.

Neste objetivo, um território da Amazônia oriental brasileira foi escolhido. A Amazônia é hoje uma região que fica no cerne da globalização, desde o incentivo do governo à sua integração na economia nacional (LOMBARD; MESCLIER; VELUT, 2006). De fato, na década de 1990, o Brasil se tornou para 
a liberalização da economia através de reformas e políticas de ajuste estrutural com o desenvolvimento, essencialmente, das exportações agrícolas. Desde então, a Amazônia se transformou em um espaço propício às produções agrícolas para a exportação. Ela é muita influenciada pelo mercado internacional e pela economia mundial (CASTRO, 2012). A região atrai inúmeros atores, especialmente grandes empresas privadas, interessadas na produção de commodities, o que gera uma forte competição pelo espaço e conflitos com atores que defendem outros modelos de desenvolvimento (agroextrativismo, agroecologia entre outros).

Um município do Baixo Tocantins na Amazônia Oriental, Mocajuba$\mathrm{Pa}$, foi escolhido por apresentar características de uma área rural isolada (tendo acesso por balsa para Belém, com parte do seu território isolado) para entender, neste caso específico, os processos de globalização e o papel do lugar como espaço de iniciativas.

Este artigo se estrutura com uma primeira parte sobre a metodologia empregada para chegar ao objetivo do trabalho. Depois, uma segunda parte apresentará as características do território estudado enfatizando os principais traços das influências da globalização hegemônica sobre o território. Enfim, a terceira parte visará enfatizar as iniciativas locais e a sua articulação com o nível global mostrando assim outras formas de globalização possíveis.

\section{1 ÁREA DE ESTUdO E METODOLOGIA}

A área de estudo, Mocajuba, é situada a $200 \mathrm{~km}$ ao sul de Belém, na beira do rio Tocantins. A população do município é de 26.731 habitantes, incluindo 18.279 na área urbana e 8.452 na área rural (IBGE, 2010a). A sua superfície é $870.8 \mathrm{~km}^{2}$. A maioria dos produtos agrícolas produzidos no município provém de uma agricultura familiar muito ativa no território. Desta forma, o território de Mocajuba pode ser dividido em quatro áreas (Figura 1):

- a área Quilombola da margem direita do rio na qual a produção principal é a farinha de mandioca; é a área a mais isolada do território mocajubense;

- as Ilhas do rio onde moram os ribeirinhos; as atividades principais sendo a pesca e o extrativismo (açaí, borracha, murumuru, cacau etc.);

- a área da Terra Firme que inclui: uma área de bacia de produção da farinha de mandioca e da pimenta do reino (o cultivo de renda) e uma área quilombola com uma produção diversificada, mas também centrada na farinha de mandioca;

- o Centro urbanizado de Mocajuba. 
Figura 1 - Zoneamento do município de Mocajuba

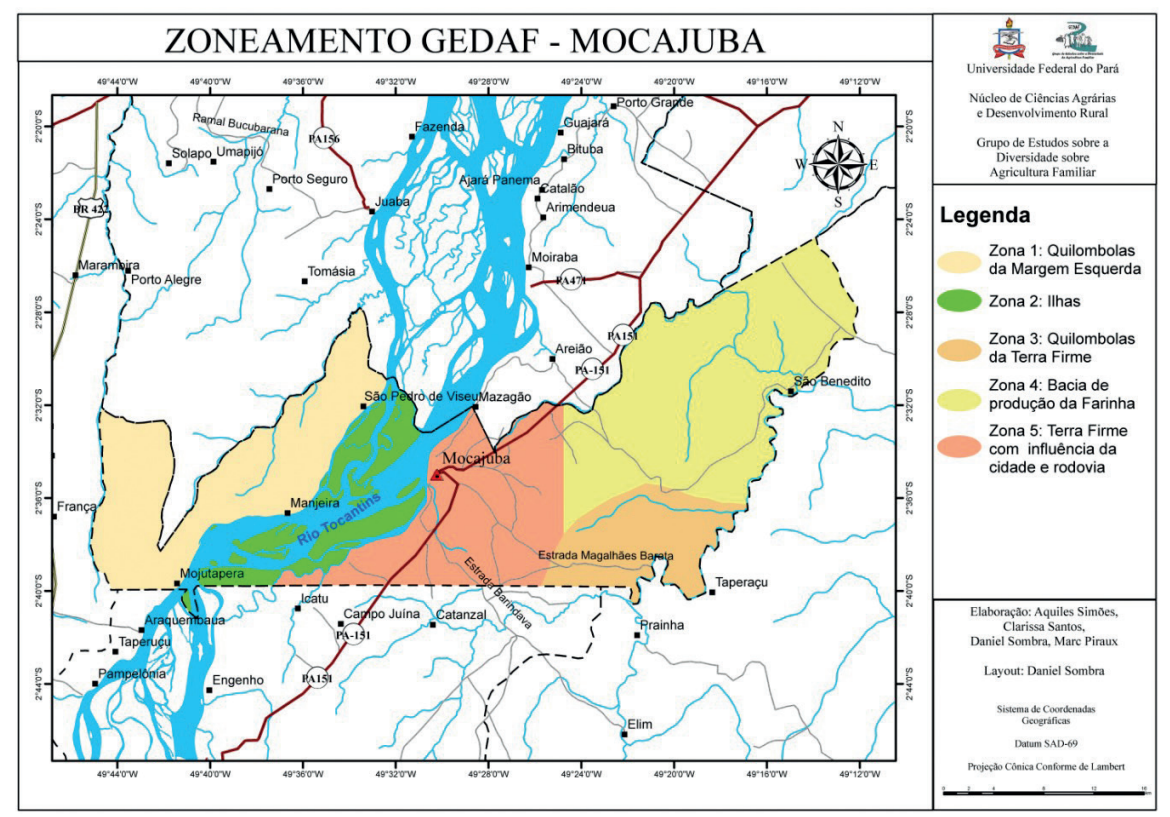

Fonte: Piraux e Cuenin (2019, p. 105).

Pelas suas características e pela sua história, Mocajuba foi considerada como um território à margem do desenvolvimento por várias razões. Em primeiro lugar, é um município bastante isolado pela necessidade de cruzar um rio com balsa para chegar a Belém desde o centro de Mocajuba. Em segundo lugar, há uma grande carência de certos serviços como saúde e educação nas zonas mais isoladas do município. Em terceiro lugar, a construção da barragem hidroelétrica em Tucuruí a montante do município nos anos 1970-1980 gerou consequências sociais e ambientais importantes, que causaram uma diminuição dos recursos pesqueiros e da produção de cultivos de várzea. Os ribeirinhos foram diretamente impactados. Em quarto lugar, a produção agrícola de renda do município, a pimenta do reino, foi tocada por uma grave crise sanitária nos anos 1990, o que diminuiu, significativamente, a produção e fortaleceu um processo de êxodo rural.

Com o aumento e a intensificação dos fluxos associados à globalização, uma análise de fluxos de diferentes tipos (produtos, pessoas, normas, capitais financeiros, informações) dentro do município e, entre este e o exterior, foi conduzida para entender as influências da globalização em vários setores e 
analisar as relações do território local com as outras escalas (regional, nacional, continental e global). Cada fluxo foi caracterizado pelas informações recolhidas por meio da análise de dados secundários e primários.

O trabalho de campo foi essencialmente dirigido na coleta de dados qualitativos e quantitativos (quando era possível) para a realização da análise dos fluxos. Pois, esses fluxos refletem as relações específicas que se estabelecem entre o município e as diferentes escalas, do regional ao global. Dados secundários, como trabalhos de pesquisa, dados de empresas e dados de administrações foram recolhidos e analisados. Os dados primários foram recolhidos por meios de observações de campo, entrevistas estruturadas e semiestruturadas, e discussões informais com anotações em caderno de campo com vários atores do território para ter uma compreensão ampla das dinâmicas territoriais.

Os atores entrevistados foram: agricultores familiares, ribeirinhos, quilombolas, representantes de associações, secretários da prefeitura, técnicos da EMATER (Empresa de Assistência Técnica e Extensão Rural) e do consórcio de empresas $\mathrm{BBB}^{1}$, moradores do centro urbano, comerciantes, representantes do Sindicato de Trabalhadores e Trabalhadoras Rurais (ST'TR) etc. Informações sobre as dinâmicas passadas foram também recolhidas, desde os anos 1985, no objetivo de entender as trajetórias do território e analisar a sua relação com o global ao longo do tempo. Dados e informações sobre projetos atuais de desenvolvimento local, também a partir das entrevistas, foram recolhidos, a fim de analisar melhor as dinâmicas e iniciativas locais existentes.

A validade das informações foi verificada pelo método de triangulação das fontes de informações. Uma restituição foi feita aos atores, para validar os resultados e completá-los. A coleta de dados foi realizada em 2014, atualizada por uma segunda série de observações e entrevistas em 2016.

\section{MOCAJUBA-PA E AS INFLUÊNCIAS GLOBALIZADAS HEGEMÔNICAS: A DOMINAÇÃO DO GLOBAL SOBRE O LOCAL}

No contexto de globalização, o município de Mocajuba se tornou globalizado, pois vários traços da "globalização perversa" (SANTOS, M., 2000) foram destacados.

\footnotetext{
Belém-Bioenergia-Brasil, consórcio de duas empresas Petrobras-Galp Energia cujo projeto era a produção de biodiesel a partir do óleo de dendê produzido no Pará.
} 


\subsection{O PODER DAS EMPRESAS MULTINACIONAIS, A COMPETITIVI- DADE E A DOMINAÇÃO DO DINHEIRO}

Esses três pontos são algumas características da globalização hegemônica e, em particular, da globalização econômica e política. A concentração do poder econômico nas mãos dessas empresas e a expansão do modelo neoliberal pelo consenso econômico entre os Estados colocaram pressão sobre os Estados para programar políticas nacionais voltadas à abertura para o mercado mundial e a economia de exportação (SANTOS, B., 2002a; SANTOS, M., 2000).

Isso se reflete no desenvolvimento de formas modernas de agricultura pelos principais produtores que trabalham diretamente com o mercado mundial: uma agricultura "científica" globalizada que obedece às técnicas globais e que atende às regras da produção econômica (SANTOS, M., 2000). A competitividade e a maximização dos lucros em curto prazo são os princípios desse tipo de agricultura. Exigente em bases científicas, técnicas e informações vindo dos centros de pesquisa e, muitas vezes, sob o controle das empresas multinacionais, instala-se certa racionalização e homogeneização das práticas com a criação de um meio técnico-científico-informacional (SANTOS, M., 2000).

Esse tipo de agricultura foi observado em Mocajuba nas grandes propriedades privadas de Terra Firme, de proprietários vindo de fora do município que implementaram sistemas agrícolas tecnificados, para o cultivo de pimenta do reino, ou outros cultivos que são vendidos ao nível internacional a grandes empresas (cacau, açaí etc.).

Também nessa mesma área, foi planejado, em 2011, a implementação de um projeto de produção de biodiesel a partir do óleo de dendê pelo consórcio de duas empresas Petrobras e Galp Energia, chamado Belém-Bioenergia-Brasil (BBB). Uma parte da produção era planejada a partir da plantação de dendê nas propriedades dos agricultores familiares da região. Um viveiro de mudas de dendê foi implementado em Mocajuba para abastecer a região. No entanto, segundo um dos responsáveis da comunicação da Petrobrás, dos 24.000ha que deviam estar plantados na pequena região, somente $230 \mathrm{ha}$ foram plantados, o que corresponde a 23 agricultores familiares contratados por uma duração de 25 anos. A execução das etapas iniciais do projeto da BBB com os agricultores mostrou uma agricultura fortemente "racionalizada", com relação ao pacote técnico, apresentado pelo coordenador do viveiro e por um dos assistentes técnicos da Petrobrás. Os agricultores dependem destas normas técnicas sob risco de quebra do contrato por não respeitar essas regras. 
Percebeu-se também a forte influência que a BBB teve no município com uma ajuda do Estado federal, e como outras empresas multinacionais podem ter no contexto de globalização, com investimentos previstos importantes em infraestruturas, mão de obra qualificada dentre outros. Segundo as entrevistas, a chegada da BBB em Mocajuba estava vista como uma esperança e um signo de um novo dinamismo para o município e, sobretudo, para o Centro e a Terra Firme, trazendo empregos e modernidade (contratação de técnicos, de trabalhadores para o viveiro etc.). Vale ressaltar que com essa dinâmica, os agricultores engajados contrataram créditos (Pronaf Eco Dendê), para implementar as áreas de dendê (8.000 reais/ha). A saída completa da BBB, em 2016, deixou várias pessoas, em particular, os agricultores engajados com a empresa, para um futuro incerto. Essa observação corrobora com a análise de Milton Santos (2000, p. 34) que critica o discurso associado à globalização hegemônica sobre as grandes empresas "apresentadas como salvadoras dos lugares" e indispensáveis.

Além da dependência do território aos capitais financeiros e as normas técnicas vindo de fora e, em particular, das grandes empresas, o poder dessas empresas se traduz também pela grande dependência do município para os produtos agroalimentares e manufaturados (televisão, celular, congelador etc.) vindo da escala nacional e internacional. Apenas alguns produtos alimentares importantes na base alimentar dos moradores são produzidos no município (setas verdes claras na Figura 2) como a farinha de mandioca e o açaí principalmente, o resto vindo de fora. Essa dependência aos produtos agroindustriais externos (seta verde escura na Figura 2) está também ligada às mudanças de sistemas de consumo alimentar dos moradores de Mocajuba que veremos no tópico a seguir.

O grande aumento de fluxos em intensidade e quantidade dos produtos agroalimentares e manufaturados desde os anos 2005 traduz o aumento da velocidade do mercado externo com as suas exigências de competitividade, mas também a chegada de uma série de programas sociais que foram desenvolvidos, em nível nacional, a partir dos anos 2002 (contando essencialmente com o programa Bolsa Família em 2003). Estes programas permitiram um aumento da renda das populações principalmente rurais e o seu acesso a novos produtos. Um membro do STTR entrevistado afirma que com a Bolsa Família: "melhorou a situação, a família já sabe que tem uma renda, e pode comprar material e comida" (informação verbal) ${ }^{2}$.

2 Informação fornecida por um membro do STTR, em 17 de julho de 2014. 
Figura 2 - Modelo dos fluxos de produtos de Mocajuba com as diferentes escalas em 2014

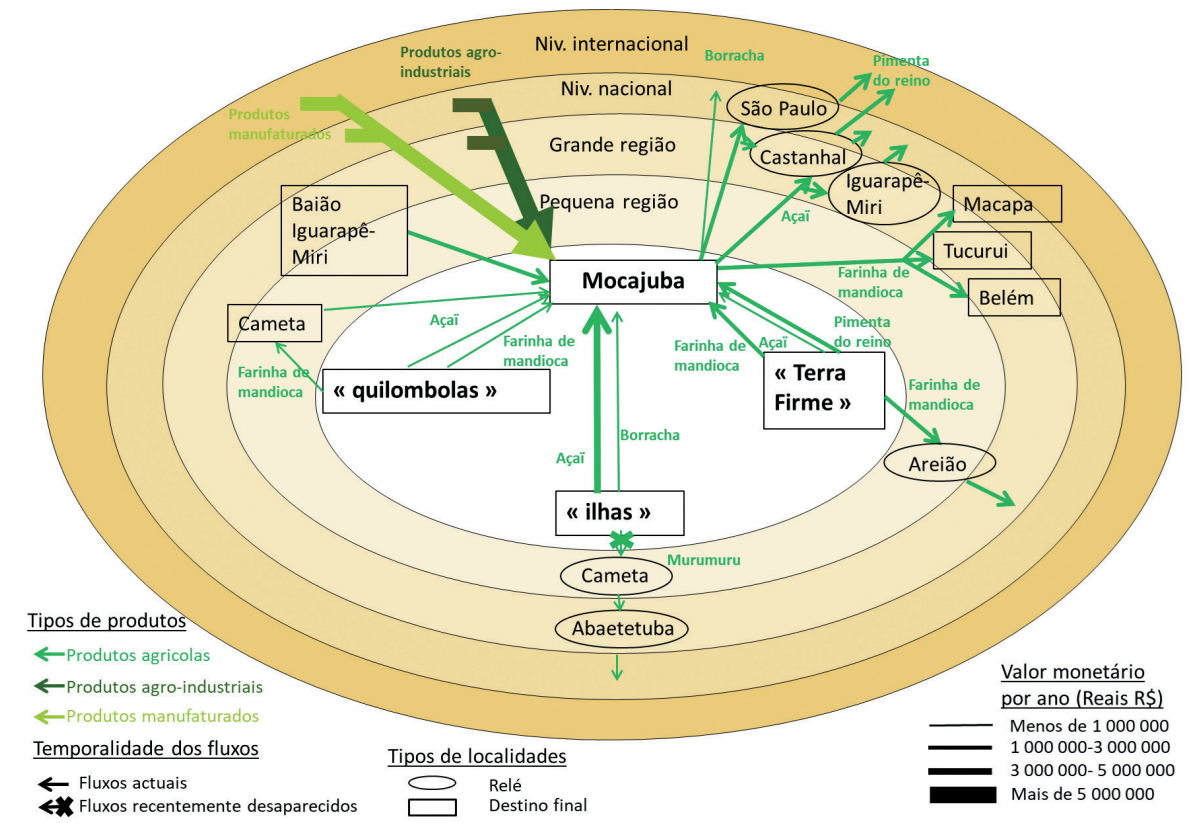

Fonte: Trabalho de campo (ago. 2014).

Todos os fluxos importantes de capitais financeiros vindos das grandes empresas e, mais geralmente, do mercado externo global está completado por fluxos financeiros "invisíveis" que se expressam pelo mercado de drogas, e pelos problemas de corrupção. Esses fluxos de dinheiro "invisíveis" são também traços da "perversidade" da globalização hegemônica.

\subsection{HOMOGENEIZAÇÃO DOS MODOS DE VIDA E DAS NECESSIDADES PELO MERCADO GLOBAL}

A globalização tende a uma homogeneização da cultura por difundir valores e significados culturais ocidentais por todo o mundo (SANTOS, B., 2002a), ameaçando diretamente as especificidades dos modelos culturais locais vinculados a lugares particulares. Ocorre uma mescla e uma hibridação cultural nos espaços gerando, em parte, uma diluição das identidades pela globalização (HAESBAERT, 1999).

Esse processo é o resultado da oferta de novos produtos do mercado global e da expansão das tecnologias da informação e da comunicação. Em 
Mocajuba, observou-se uma multiplicação dos fluxos de produtos desde 1985 e, sobretudo, nos anos 2005, com a chegada da eletricidade no Centro e a implementação da Bolsa Família. Em particular, como foi dito antes, percebeu-se um aumento significativo de fluxos de produtos agroalimentares, manufaturados e de informações vindo de fora do município, quer seja de um nível nacional quer internacional.

Este aumento da oferta está diretamente ligado a duas outras características da globalização hegemônica, o consumismo e a onipresença da informação veiculada pela mídia, como ressaltou as entrevistas. Em Mocajuba, esse fenômeno pode ser ilustrado pela constante presença de um som alto composto de músicas e propagandas difundidas durante o dia nas ruas do Centro da cidade. Os moradores da cidade ou habitantes das zonas rurais em passagem pelo Centro são, obrigatoriamente, expostos a esses anúncios em áudios que estão geralmente voltados à propaganda para o consumo de produtos das numerosas lojas presentes no Centro de Mocajuba. Com esta importante parte das informações que procura convencer a consumir pela publicidade, a globalização impõe novos modelos e lógicas nos territórios e joga um papel unificador (SANTOS, M., 2000).

Segundo o discurso das pessoas, a forte oferta em vários produtos de consumo e de serviços, o aumento da renda com a Bolsa Família e o acesso à informação foram fatores de modificação dos modos de vida e sistemas de consumo alimentar em Mocajuba. A cotidiana refeição dos produtos locais (açaí, peixe e mandioca) dos 30 anos atrás foram substituídos pela atual refeição de arroz, feijão e carne, alimentos produzidos fora do município. Assim, uma centenária quilombola e ribeirinha opõe o "século velho" no qual se consumia a sua própria produção, ou seja, farinha de mandioca, tapioca, laranja, açaí, peixe, ao "século novo" quando, segundo ela, a vida das pessoas melhorou com a Bolsa Família e a aposentadoria com os quais podiam comprar outros alimentos ou produtos. Um morador das Ilhas de 76 anos, confirma que há 30 anos "comíamos peixe, açaí e farinha todo dia, feijão e arroz era uma vez por ano, hoje, comemos todo dia" (informação verbal) ${ }^{3}$. Além disso, com a construção da barragem de Tucuruí e a diminuição dos recursos pesqueiros, uma moradora do território Quilombola reforça ainda mais o fato que agora comer peixe é raro: "quando consegui comer peixe, fica naquela alegria" (informação verbal) ${ }^{4}$.

A chegada da eletricidade nas Ilhas, em 2015, melhorou a qualidade de vida dos moradores do "século novo", como enunciado pela centenária, mas teve diferentes repercussões no modo de vida: o aumento da duração de tempo

\footnotetext{
Informação fornecida por um morador da Ilha, em 25 de abril de 2014.

4 Informação fornecida por uma moradora do território quilombola, em 7 de junho de 2014.
} 
de visualização da televisão e o desencadeamento do consumo de numerosos produtos eletrônicos como a máquina de lavar, a geladeira, o computador até o arcondicionado e pontos de $W i$-Fi como foi observado em algumas casas das Ilhas.

Outra forma de penetração da globalização hegemônica em Mocajuba é o aumento crescente de fiéis de igrejas evangélicas e pentecostais. Esse fenômeno é particularmente visível na Amazônia, mas parece estar ainda mais presente em Mocajuba com uma porcentagem de $27,3 \%$ de pessoas que se declaram de confissão evangélica (IBGE, 2010a) contra 22,2 \% em 2010 no Brasil (IBGE, 2010b). Segundo Dejean (2008), este aumento rápido se explica nos processos característicos da globalização, especificamente na expansão das tecnologias de informação e de comunicação.

De fato, essas igrejas usam, massivamente, os meios de comunicação modernos, como a internet ou a rádio no caso de Mocajuba, para difundir os seus programas e estender as suas influências, criando fluxos de informações importantes. Apoiam-se também em redes globais de organização que permitam reforçar as igrejas locais dentre outros por fluxos financeiros massivos. Um quilombo ressaltou que isso implicou profundas modificações nas relações entre as pessoas, por exemplo, nas redes de trabalho, deixando os antigos grupos para redes de igrejas.

A instalação crescente dessas religiões é ligada ao processo de globalização também por propor apoio às pessoas mais afetadas pelos diferentes problemas sociais instalados no município, podendo ser vistos como os marginalizados da globalização. A instalação rápida dessas igrejas em todas as partes do município é também um signo da homogeneização dos modos de vida de Mocajuba.

Para resumir, a modificação e, especificamente, a homogeneização dos modos de vida e das necessidades locais em Mocajuba ocorre. O mercado global e as novas técnicas de comunicação e de informação, oferecendo e difundindo novos modelos, impactaram diretamente as condições locais: é o produto do globalismo localizado, uma das formas das globalizações hegemônicas enunciadas por Boaventura de Sousa Santos (2002a).

\subsection{A FRAGMENTAÇÃO DO TERRITÓRIO}

Em Mocajuba, observou-se um processo de diferenciação interna no território. Na caracterização do município, nós já havíamos destacado quatro áreas a partir do zoneamento enfatizado por Piraux e Cuenin (2019), mas, no contexto de globalização, essas áreas se diferenciaram ainda mais. De fato, como nós já mostramos anteriormente, as Ilhas do município estão em um novo dinamismo: 
os padrões de vida mudaram com a criação de assentamentos agroextrativistas, o Bolsa Família, a chegada da eletricidade, o crescimento da produção de açaí. Os fluxos de pessoas das Ilhas para o centro são numerosos e regulares com os barcos hoje motorizados. O Centro e os seus produtos de consumo e serviços são relativamente próximos e acessíveis. A capacidade de mobilidade dos moradores das Ilhas é grande em comparação com os do território Quilombola do outro lado do rio. Com as entrevistas e observações de campo, identificaram-se fluxos de pessoas de cerca de 400 pessoas por dia vindo das Ilhas quanto do território Quilombola, este fluxo diminui a 100 pessoas por semana.

De fato, este território Quilombola do outro lado do rio parece ainda mais isolado. Nele, observa-se também uma diferença de velocidade com os movimentos gerais. Apesar das tentativas do governo federal, com a oportunidade de reconhecimento do território como quilombola e todas as vantagens associadas e das ONGs para dinamizar o território, esse território fica "na lentidão" em comparação aos movimentos globais. Pois, fica ainda muito isolado e na margem dos outros territórios do município. Primeiro, segundo os dados de campo, o processo de certificação do território Quilombola demorou 7 anos, principalmente por falta de informações sobre os processos administrativos a serem realizados. Além disso, um dos membros do STTR e moradora deste território afirmou que a prioridade para o acesso às políticas públicas existe, mas, na realidade, não são muito eficazes porque estes territórios "continuam a serem zonas isoladas e de acesso complicado" (informação verbal) ${ }^{5}$. A distância ao Centro e aos seus serviços como a saúde e a educação penaliza ainda mais os atores desse território. A descontinuidade das ações das ONGs e, com isto, a descontinuidade do acesso a certas informações limitam também os benefícios destas ações. A capacidade de mobilidade das pessoas e o acesso às informações é diminuído: os fluxos de pessoas com o Centro e os fluxos de informações com os outros espaços (local, nacional, internacional) são de pouca intensidade.

Enfim, na área da Terra Firme (exceção do território quilombola), que era próspera nos anos 80 com o cultivo da pimenta do reino, fica hoje, em uma dinâmica diferente depois da crise sanitária nos anos 90 que fortaleceu o êxodo rural e da constante flutuação do preço do produto. Com o melhor acesso a Mocajuba desde a capital paraense (construção da PA-151), a violência e o mercado ilícito de drogas se desenvolveram bastante na Terra Firme e na periferia do Centro, outra consequência da globalização hegemônica no território e particularmente na periferia do Centro e na Terra Firme. A maioria das pessoas entrevistadas do Centro ressaltou estas problemáticas.

5 Informação fornecida por uma moradora do território quilombola, em 10 de junho de 2014. 
Além da pimenta, conforme já ressaltado, a chegada da BBB prometia levar certo dinamismo na Terra Firme (escritórios, viveiro, contratos), ou seja, o consórcio BBB queria impor a sua própria velocidade nessa área principalmente povoada por agricultores familiares, mas foi confrontada a realidade da área, como foi ressaltado por um dos assistentes técnicos da Petrobrás: falta de infraestruturas rodoviárias, dívidas dos agricultores, agricultores sem título fundiário etc. Diante dessa situação não prevista, o projeto falhou e em 2016, a BBB tinha saído completamente de Mocajuba deixando a área da Terra Firme e os seus moradores em uma situação ainda mais vulnerável.

Deve-se notar também que alguns grandes proprietários privados de Mocajuba ou da região investem na Terra Firme na cultura de pimenta, na criação de gado ou no desenvolvimento da cultura de açaí. A chegada desses tipos de investidores representa certa ameaça para a agricultura familiar local pela apropriação das terras e dos recursos, o que gera alguns conflitos nessa parte do município.

Apesar dos processos de uniformização e homogeneização ligados à globalização, processos de diferenciação também ocorrem ao mesmo tempo. Como enfatiza Milton Santos (2008, p. 39), "os territórios tendem a uma compartimentação generalizada [...] e a um processo de fragmentação que rouba às coletividades o comando do seu destino" pelas ações hegemônicas da globalização. De fato, os movimentos gerais globais se chocam com os movimentos particulares dos lugares: as diversas velocidades são incompatíveis. Apesar dos portadores das velocidades extremas quererem difundir as infraestruturas para induzir a mesma velocidade aos outros atores, ocorre uma seleção da qual resulta separação dos espaços: os da pressa e os da lentidão (SANTOS, M., 2000).

Isso tem a ver com a ideia da compressão do tempo-espaço supostamente induzida pela globalização. Os diferentes grupos sociais têm relacionamentos distintos com a mobilidade: a velocidade alcance unicamente certos grupos sociais. Assim, existe uma diferenciação social complexa em relação à mobilidade temporal e espacial segundo a capacidade de movimento, de comunicação, de controle etc. das pessoas, o que cria diferentes efeitos e significações das distâncias associados a processos de empoderamento ou enfraquecimento. A mobilidade de alguns grupos gera o aprisionamento espacial de outros grupos, ou seja, a criação de relações de poder (MASSEY, 2000; SANTOS, B., 2002a; SANTOS, M., 2000). 


\subsection{AS FALTAS DO ESTADO E DAS SUAS AÇÕES DE REGULAÇÃO A DIFERENTES NÍVEIS}

Em Mocajuba, constatou-se uma falta de regulação do Estado. O governo federal criou programas (Bolsa Família, criação de assentamentos, seguro de defesa durante período que não se pode pescar etc.) para compensar alguns problemas sociais, mas o funcionamento interno pode ser questionado. Os atores entrevistados afirmaram que existe uma falta de planificação e de acompanhamento dos poderes públicos locais nas áreas da educação e da saúde particularmente.

A dificuldade de implementar alguns conselhos de participação como o Conselho Municipal de Desenvolvimento Rural Sustentável foi também ressaltado, durante a pesquisa, o que mostra a dificuldade de inclusão da sociedade civil nas escolhas públicas. A falta de recursos da EMATER que tem muita dificuldade para atingir os agricultores das zonas rurais mais isoladas e conduzir ações de acompanhamento foi também destacado pelo STTR. Assim, observou-se de forma geral uma dificuldade de transformar as políticas criadas pelo governo federal em políticas de inserção social em vez de assistência social.

Boaventura de Sousa Santos (2002), ao tratar da globalização política dominante e dos seus traços principais, mostra o papel crescente das formas de governo super estatal. Segundo o autor, os Estados periféricos ou semiperiféricos são pressionados pelos Estados hegemônicos e/ou pelas instituições internacionais para a criação de requisitos normativos e institucionais para o modelo de desenvolvimento neoliberal do qual resulta uma diminuição da autonomia e da soberania desses Estados. O autor destaca que esse fenômeno toma uma forma visível quando ocorre uma destruição institucional e normativa que afeta a regulação estatal da economia e a legitimidade global do Estado para organizar a sociedade.

Resumindo essa parte, a partir da análise de diferentes elementos que caracterizam a globalização hegemônica, foi destacado a penetração da lógica dominante do global no município e os seus impactos sobre as condições locais pelo intermediário de um processo de globalismo localizado (SANTOS, B., 2002a). O poder das grandes empresas, dos fluxos financeiros associados, a competitividade imposta pelo mercado global e a falta de regulação do Estado desintegram as condições locais. Notou-se, em particular, nesse processo a fragmentação e a diferenciação do território em quatro áreas com velocidade de caminho muito diferente diante dos movimentos globais, a homogeneização dos modos de vida e a modificação dos sistemas de consumo. 


\section{REPENSAR O LOCAL E AS SUAS RELAÇÕES COM O GLOBAL PARA OUTRAS FORMAS DE GLOBALIZAÇÃO}

Diante dessa aparente dominação do global no local, existem iniciativas locais no município que, embora geralmente invisibilizadas pela lógica da escala do global, são importantes para o desenvolvimento do território e para pensar em outras formas de globalização.

\subsection{REVALORIZANDO OS RECURSOS LOCAIS COM UMA ARTICULAÇÃO GLOBAL-LOCAL}

Essas estratégias revalorizando os recursos locais foram sobretudo visíveis nas Ilhas do município. Dois exemplos podem ser explicados, para ilustrar esse fenômeno: o desenvolvimento do cultivo de açaí e da exploração da borracha. Nestes últimos cinco anos, de fato, foi observado um fluxo de venda crescente das Ilhas para o Centro de Mocajuba e depois para o nível regional e nacional ou internacional.

O cultivo de açaí de várzea é tradicional nas Ilhas e é representativo do agroextrativismo realizado nessa área. Segundo vários atores do município (secretaria da agricultura, membros do STTR, membros de associações), a produção de açaí se desenvolveu de fato bastante nesses últimos anos, em resposta ao crescimento da demanda nacional e internacional, o que se traduziu por novos canais de comercialização, tal como a venda direta para as empresas de transformações para vendas nacionais e exportações internacionais além da venda tradicional aos atravessadores para o mercado regional.

Mas, é importante salientar, que apesar do aumento de produção, em parte vendida agora para empresas que podem ser de exportações, o sistema de técnicas e práticas adotado fica no domínio dos ribeirinhos e não está imposto por agentes externos. As práticas são baseadas no lugar e nos conhecimentos locais dos agroextrativistas: são eles que adaptam as suas técnicas para responder à demanda considerando os seus próprios modelos locais de representações e conhecimentos. Como exemplo, podemos citar a invenção de uma tecnologia social por um ribeirinho das Ilhas de Mocajuba para derrubar rapidamente e facilmente os frutos de açaí dos cachos. Essa dinâmica endógena mostra a capacidade dos atores, aqui, os agroextrativistas de Mocajuba, de responder ao mercado global com uma cultura tradicional sem estarem subordinados às normas técnicas globais. 
No entanto, não é para minimizar os riscos ligados à crescente demanda nacional e internacional pelo açaí, como o risco de monocultura tanto nas Ilhas quanto na Terra Firme com a implementação de áreas novas de açaí irrigado. O desafio se encontra, uma vez mais, na regulação desses fenômenos que podem afetar rapidamente um território por construir manejos sustentáveis e adequados às condições locais.

O segundo exemplo interessante é o da produção de borracha natural, que sempre foi uma produção muito explorada, a partir do final do século XIX, com a invenção do pneu. Em Mocajuba, a produção foi parada nos anos 1980 por uma forte concorrência dos países asiáticos. Em 2008, a produção foi reativada nas Ilhas pela vontade da empresa Michelin e pelo intermediário de uma cooperativa de Belém, associado à sinergia entre o governo com a política de preço garantido e as iniciativas pessoais dos extrativistas.

De fato, depois da criação dos assentamentos agroextrativistas nas Ilhas e da proposta da Michelin, em 2010, os produtores criaram uma organização especial para articular esse processo e acessar a política de preço mínimo Companhia Nacional de Abastecimento (CONAB). O presidente da associação criada, também membro do STTR, explicou como esta permite representar os produtores e facilitar os procedimentos administrativos para a obtenção do subsídio do governo.

Neste exemplo, nota-se a importância da dimensão multinível, da articulação forte entre o local e o global e entre atores diferentes (sociedade civil, Estado, empresa privada). De fato, uma demanda externa vinda de uma empresa multinacional, os atores locais se organizaram para controlar o processo, fortalecer a posição dos produtores e os seus direitos em relação aos demais atores externos, e então, para criar uma relação mais equilibrada diante do poder da grande empresa. Além dessa interação entre os produtores e os outros atores da cadeia, a sinergia entre o poder público e as iniciativas locais é outro aspecto fundamental desse exemplo.

Com esses exemplos, mostrou-se como, diante do mercado global, os atores locais do município se adaptaram e desenvolveram estratégias revalorizando os recursos locais, ou seja, novas forças foram encontradas no entorno imediato das pessoas (SANTOS, M., 2000). Observou-se que as especificidades do lugar voltam a ser consideradas para desenvolver novas práticas (ESCOBAR, 2005). Corresponde a uma reapropriação do lugar, tanto das características do meio físico quanto as da esfera social, com a criação de vínculos específicos com o lugar. Estratégias de identificação e ativação de recursos naturais locais 
como descritas na teoria da especificação de recursos de Pecqueur (2005) foram realizadas pelos atores locais em articulação com atores de outras escalas.

Portanto, articular várias escalas, saberes, lógicas de produtividade e atores torna possível uma diversificação e multiplicação das experiências disponíveis e possíveis. No entanto, essa articulação é possível graças a uma tradução das práticas das diferentes esferas e escalas que se cruzam para construir novas possibilidades. Essa tradução, que pode ser realizada por representantes de grupos sociais que compreendem de maneira profunda os processos, é feita quando há conjugação das oportunidades, como neste caso aqui (SANTOS, B., 2002b). As lideranças sindicais podem ser um desses atores capazes de fazer essa tradução, o que lhes coloca em uma posição importante para o desenvolvimento territorial. No final, essa articulação, que pode trazer conflitos e diálogos, permite a emergência de novas experiências contra hegemônicas transformadoras e evita certo desperdício (SANTOS, B., 2002b).

\subsection{PROMOÇÃO DOS PRODUTOS ALIMENTARES LOCAIS PARA UM EQUILÍBRIO ENTRE O LOCAL E O GLOBAL}

No município, a maioria dos atores ressaltou a falta de organização coletiva (por exemplo, não existe cooperativa em Mocajuba) e de articulação entre as diversas instituições (secretarias de prefeitura, sindicatos, associações etc.). Isto continua a ser problemático, em particular, para o estabelecimento de novos projetos locais e a criação de canais de comercialização alternativos. No entanto, salientam-se o desenvolvimento da comercialização local de alguns produtos do território, por exemplo, a da farinha de mandioca da Terra Firme vendida em parte no Centro graças a um melhoramento da sua qualidade (SOUSA; PIRAUX, 2015).

Além disso, na última fase de observação (em 2016), teve uma dinamização na construção e implementação do PNAE (Programa Nacional de Alimentação Escolar) que pode conduzir à criação de novos fluxos de produtos alimentares no seio do município, à valorização de produtos que ficam geralmente nas comunidades ou nas propriedades e, portanto, à redução da dependência aos alimentos externos. Neste objetivo, a secretaria da agricultura tentou iniciar projetos com os agricultores da Terra Firme para promover a produção local para uma utilização futura no PNAE. A secretaria exemplificou citando projetos de criação de peixe e de distribuição de sementes de feijão que foram iniciados. Outros produtos locais como a mandioca e os seus derivados, o maracujá e o jerimum devem também estar integrados ao PNAE. 
Além disso, o PNAE trabalhou também com a criação de galinhas caipiras que se desenvolveu bastante no município por iniciativa própria de alguns agricultores voltados ao espaço do STTR. Mesmo se as quantidades vendidas no mercado são mínimas em comparação com o volume de frangos industriais, esta iniciativa é um exemplo concreto de iniciativas locais, com potencialidade de crescimento no município no caso de um apoio dos poderes locais. Entre as duas fases de campo, observou-se um pequeno aumento do número de agricultores criando galinhas caipiras (de 6 a 10 famílias envolvidas) e um crescimento da demanda.

No entanto, vale ressaltar alguns riscos aos quais essas iniciativas estão expostas frente aos movimentos da globalização hegemônica. De fato, colocando novos produtos no mercado local que fazem concorrência aos produtos agroindustriais, o risco maior é que as grandes empresas fazem cair os preços dos seus produtos para serem ainda mais competitivos. Isso foi, segundo as falas do STTR, o que aconteceu quando um dos antigos secretários da agricultura começou a desenvolver a criação de galinhas caipiras com os agricultores. Outro risco a considerar é que, ao valorizar os produtos locais, os preços desses produtos poderiam aumentar, o que faria também voltar no círculo vicioso dos consumidores comprarem os produtos agroindustriais por serem mais baratos do que os produtos locais.

Dessa forma, apesar de um balanço entre os produtos alimentares produzidos no município e os produtos agroindústrias vindos de fora ainda serem muito desequilibrados, notam-se iniciativas dos atores locais com potencialidade para o futuro mesmo se ainda frágeis. Nessa dinâmica, vamos salientar, em particular, uma nova perspectiva que vem com um novo olhar para valorizar o lugar, a agroecologia.

\subsection{AS REDES TRANSLOCAIS DE AGROECOLOGIA E A PRODUÇÃO DE GLOCALIDADES ALTERNATIVAS}

A agroecologia ${ }^{6}$ apresenta possibilidades para valorizar o lugar por promover uma agricultura ecológica enraizada nos recursos naturais e nas condições locais. Ao contrário da "agricultura científica globalizada" baseada nos princípios indústrias e em normas de uma ciência e técnicas globais na busca da maximização da produtividade em curto prazo, a agroecologia se baseia na

6 Definida como ciência, movimento e prática (WEZEL et al., 2009), valorizando antes de todo os recursos locais em uma vontade de coconstrução de conhecimentos e sistemas mais resilientes. 
dimensão local valorizando as experiências locais e ativando o potencial endógeno do lugar para construir novas formas de agricultura (GUZMÁN, 2005).

Em Mocajuba, o movimento agroecológico é ainda bem fraco, mas alguns elementos interessantes se destacam. A ONG Associação Paraense de Apoio às Comunidades Carentes (APACC) tem uma sede no município vizinho há 18 anos e organiza projetos e ações em parceria com a UFPA e outras ONGs sobre agroecologia e economia solidária na região como, por exemplo, o Fórum da Economia Solidária ou projetos no território Quilombola de Mocajuba.

No ano de 2016, o STTR iniciou grupos de trabalho sobre a agroecologia e, nesse mesmo ano, lançou feiras dos produtores locais mensais. Depois da segunda edição, essa iniciativa, no entanto portadora de esperança para novas forças de dinamismo do território e os seus produtores locais, fracassou por uma razão que um dos membros do ST'TR entrevistado levantou: "os agricultores quanto os consumidores faltam de sensibilização" (informação verbal) ${ }^{7}$ quanto à importância da produção e do consumo local dos produtos. De fato, segundo esta mesma pessoa, teve grande dificuldade em mobilizar tanto os produtores quanto os consumidores e observou que eram os consumidores os mais educados (médicos, professores etc.) que vinham comprar os produtos na feira.

A partir disso, o ST'TR organizou oficinas sobre agroecologia com grupos de mulheres para sensibilizar e informar sobre o que é a agroecologia. De fato, este membro do STTR entrevistado confia e aposta nas mulheres com quem tem laços de confiança. Essa primeira iniciativa foi se desenvolvendo com a realização de seminários mais amplos sobre vários temas ligados à agroecologia em parceria com a UFPA e a ONG FASE. Pensou-se na realização de uma feira agroecológica no município, mas ainda não está implementada por esperar emancipar mais agricultores e consumidores sobre o assunto.

Nota-se neste exemplo que, mesmo se o movimento agroecológico ainda está fraco no município, uma rede local está se construindo (STTR, UFPA, ONG), a partir de duas instituições (UFPA, ONG) que atuam localmente, mas que já estão conectadas com um movimento mais global (um fórum de economia solidária, por exemplo) e que já lidam com o tema. Isso anuncia esperança para projetos locais futuros. De fato, a articulação dos diversos atores em redes é essencial para a realização de trabalhos colaborativos. $\mathrm{Na}$ Zona da Mata mineira, Cardoso e Ferrari (2006) enfatizaram como as interações entre ONG, universidade e organizações de agricultores foram primordiais para a construção do conhecimento agroecológico e a realização de projetos participativos.

Informação fornecida por um membro do STTR, em 14 de outubro de 2016. 
Além disso, pode-se pensar em uma conexão futura maior com outras redes agroecológicas de outros locais e/ou de escala maior. As redes agroecológicas conectadas de maneira muito ampla entre locais, regiões e países no mundo permitem trocas de experiências e práticas inovadoras para o território. Portanto, a emergência do movimento agroecológico em Mocajuba e a sua estruturação dentro de redes é um signo promissor para outras formas de desenvolvimento do território.

De fato, em vários exemplos no mundo, a agroecologia se desenvolveu e se expandiu por organizações locais, $\mathrm{ONG}$, associações e redes camponesas. Essas redes de diferentes atores são espaços de aprendizagem, de reflexão coletivas e participativas que permitem a coconstrução de saberes e o seu compartilhamento por vias horizontais. A articulação dos diversos atores em redes é essencial para a realização de trabalhos colaborativos dessa natureza. Ao articular e expandir as várias iniciativas locais a uma escala maior, as redes da agroecologia é uma forma de globalização contra hegemônica, produtoras de glocalidades alternativas promovendo a defesa do lugar e da natureza (ESCOBAR, 2004, 2005; SANTOS, B., 2002b).

Destacaram-se nesta parte algumas iniciativas locais que ocorreram no município de Mocajuba, e a maneira de como elas se integram com o global para um melhor equilíbrio entre o global e o local e uma diminuição da dicotomia global/local. Assim, alguns exemplos mostraram como o local contra hegemônico acontece globalmente e como o global contra hegemônico acontece localmente. Ambas as estratégias de localização e de globalização contra hegemônicos são de importância para contrabalançar os impactos da globalização hegemônica.

\section{CONSIDERAÇÕES FINAIS}

$\mathrm{Na}$ análise conduzida em um município considerado como marginalizado, nós destacamos, como a globalização do "vencedor", ou seja, a globalização neoliberal capitalista, impacta diretamente o território. Os fluxos financeiros, de pessoas, de produtos e de informações cresceram muito dentro do município e entre este e o exterior. Eles geram uma diferenciação de posição entre o global dominante e o local dominado. Para contrapor o peso das influências dessa globalização, ressaltou-se a importância de revalorizar o local e as suas diversas experiências para reintroduzir uma simetria entre o global e o local, e assim dar visibilidade às iniciativas locais como estratégias de resistência e soluções locais para problemas globais. 
Algumas iniciativas locais da sociedade civil, e do poder público local (projetos galinha caipira, criação de peixe, distribuição de sementes, feiras de produtores locais etc.) tentam criar algumas dinâmicas para uma maior autonomia do território. No entanto, para realmente sair da dicotomia global/local e chegar a novas práticas e conhecimentos, a articulação das escalas se revelou essencial. Assim, novos focos nos recursos locais (desenvolvimento crescente do cultivo açaí, retomada do extrativismo de borracha), adaptações dos sistemas de produção de cultivo tradicional diante do contexto nacional e global (aumento da qualidade da farinha de mandioca, desenvolvimento do cultivo de açaí nos SAFs), sinergias entre uma nova organização coletiva e o poder público (no caso do retomada do extrativismo da borracha ou no exemplo do PNAE), consolidação de mercados a diferentes escalas e novas estratégias baseadas em redes agroecológicas multiníveis foram destacadas por ter um potencial muito grande para o desenvolvimento do município. Como enfatiza a ecologia das transescalas de Boaventura de Sousa Santos (2002b), parece necessário revalorizar o lugar e as suas experiências e mais do que isso, rearticular o lugar e o global.

No entanto, é sem contar as fragilidades, riscos e ameaças existentes. Essas novas experiências locais precisam ser reforçadas e institucionalizadas para criar novas dinâmicas no território. Com isso, o papel do Estado, a partir de quadros políticos local, regional e nacional, é fundamental.

Primeiramente, o papel regulador do Estado é necessário para assegurar uma melhor gestão das influências globalizadas e evitar os abusos como foi destacado, em particular, no caso do projeto da BBB e com as massas de produtos notadamente alimentares vindo dos outros níveis (regional, nacional, internacional). Em segundo lugar, para lidar com os efeitos dos fluxos da globalização como a homogeneização dos modos de vida e as suas implicações (problemas com o lixo, a saúde, o êxodo rural) ou ainda a fragmentação do território, investimentos nos serviços básicos de educação, formação e saúde deveriam ser prioritários para todas as diferentes partes do município. Assim, estes investimentos permitiriam informar e sensibilizar as populações sobre os problemas identificados como consequências da globalização hegemônica e, ao mesmo tempo, valorizar as diferentes culturas presentes no território mocajubense e, portanto, tornar os moradores mais cidadãos do que consumidores. Além disso, é preciso que essas ações do Estado nas várias escalas sejam associadas a um acompanhamento para diminuir os riscos ligados às influências globalizadas, consolidar as experiências locais novas e promover a integração das diferentes populações.

Enfim, o reforço das competências locais, a formação de líderes locais e o fortalecimento da ação coletiva é um ponto particularmente importante 
para se criar novas dinâmicas e estruturas de governança. De fato, destacamos a importância dos líderes locais (membros do STTR ou de associações moradores de diversas zonas do território) para jogar o papel de tradutor entre os diferentes atores (secretaria da agricultura, agricultores, empresas privadas, ONG etc.), práticas de diversas esferas (sociedade civil, poder público, esfera privada) e escalas (local, regional, nacional, internacional) e assim tornar possível a emergência de novas experiências. Portanto, as perspectivas multiníveis e multi atores se tornam essenciais para a construção de novas experiências locais e o desenvolvimento territorial do município.

\section{REFERÊNCIAS}

BRUNET, R.; DOLLFUS, O. Le déchiffrement du monde. In: BRUNET, R.; DOLLFUS, O. (org.). Mondes nouveaux, géographies universelles. Montpellier: Reclus; Paris: Fayard, 1990. p. 9-271.

CARDOSO, I. M.; FERRARI, E. A. Construindo o conhecimento agroecológico: trajetória de interação entre $\mathrm{ONG}$, universidade e organizações de agricultores. Revista Agriculturas, [S. l.], v. 3, n. 4, p. 28-32, 2006.

CASTRO, E. Amazônia: sociedade, fronteiras e políticas. Caderno $\mathbf{C R H}$, Salvador, v. 25, n. 64, p. 9-16, 2012.

DEJEAN, F. L'évangélisme et le Pentecôstisme: des mouvements religieux au coeur de la mondialisation. Géographie et cultures, Paris, n. 58, p. 43-61, 2008.

DOLLFUS, O. La mondialisation. Paris: Presses de Sciences Po, 1997.

DURAND, M.-F.; LÉVY, J.; RETAILLÉ, D. Le monde espace et systèmes. Paris: Presses de la Fondation Nationale des Sciences Politiques, 1992.

ESCOBAR, A. Actores, redes e novos produtores de conhecimento: os movimentos sociais e a transição paradigmática nas ciências. In: SANTOS, B. S. (org.). Conhecimento prudente para uma vida decente. São Paulo: Cortez, 2004. p. 639-666.

ESCOBAR, A. O lugar da natureza e a natureza do lugar: globalização ou pós-desenvolvimento? In: LANDER, E. (org.). Colonialidade do Saber: eurocentrismo e ciências sociais. Perspectivas latino-americanas. Buenos Aires: CLACSO, 2005. p. 33-49.

GIDDENS, A. Sociology. Oxford: Polity Press, 1990. 
GUZMÁN, S. Agroecologia e desenvolvimento rural sustentável. In: AQUINO, A. M.; ASSIS, R. L. (org.). Agroecologia: princípios e técnicas para uma agricultura orgânica sustentável. Brasília, DF: Embrapa, 2005. p. 101-132.

HAESBAERT, R. Identidades territoriais. In: ROSENDHAL, Z.; CORREA, R. L. (org.). Manifestações da cultura no espaço. Rio de Janeiro: EDUERJ, 1999. p. 149-168.

HELD. Global transformations: politics, economics and culture. Cambridge: Polity Press, 1999.

IBGE. Mocajuba. IBGE, Rio de Janeiro, 2010a. Disponível em: https:/ / cidades. ibge.gov.br/brasil/pa/mocajuba/panorama. Acesso em: 9 nov. 2017.

IBGE. Brasil. IBGE, Rio de Janeiro, 2010b. Disponível em: https: / cidades.ibge. gov.br/brasil/pesquisa/23/22107?detalhes=true. Acesso em: 15 set. 2018.

LOMBARD, J.; MESCLIER, E.; VELUT, S. La mondialisation côté Sud: acteurs et territoires. Paris: IRD Éditions, 2006.

MASSEY, D. Um sentido global do lugar. In: ARANTES, A. A. (org.). O espaço da diferença. Campinas: Papirus, 2000. p. 176-184.

MONTERO, P. Globalização, identidade e diferença. Novos Estudos Cebrap, São Paulo, n. 49, p. 47-64, 1997.

PECQUEUR, B. Desenvolvimento territorial: uma nova abordagem dos processos de desenvolvimento para as economias do Sul. Raízes, Campina Grande, v. 24, n. 1/2, p. 10-22, 2005.

PIRAUX M.; CUENIN P. H. C. M. Evolução das conexões entre produção e consumo e seus impactos sobre as dinâmicas de um território: o caso de Mocajuba na Amazônia oriental - PA. Redes, Santa Cruz do Sul, v. 24, n. 3, p. 101-117, 2019.

RAFFESTIN, C. Ecogénèse territoriale et territorialité. In: AURIAC, F; BRUNET, R. (org.). Espaces, jeux et enjeux. Paris: Fayard, 1986. p. 175-185.

RAINELLI, P. L'agriculture de demain: gagnants et perdants de la mondialisation. Paris: Éditions du Félin, 2007.

REYNAUD, A. Société, espace et justice. Paris: Presses Universitaires de France, 1981.

SANTOS, B. S. A globalização e as ciências sociais. 2. ed. São Paulo: Cortez, $2002 a$. 
SANTOS, B. Para uma sociologia das ausências e uma sociologia das emergências. Revista Crítica de Ciências Sociais, Coimbra, v. 63, p. 237-280, 2002b.

SANTOS, M. Por uma outra globalização: do pensamento único à consciência universal. Rio de Janeiro: Record, 2000.

SANTOS, M. A natureza do espaço: técnica e tempo, razão e emoção. 4. ed. São Paulo: EDUSP, 2008.

SOUSA, F. F; PIRAUX, M. A construção social da qualidade da farinha de mandioca em comunidades rurais na Amazônia paraense. Novos Cadernos NAEA, Belém, v. 18, n. 3, p. 199-222, 2015

WEZEL, A. et al. Agroecology as a science, a movement and a practice. Sustainable Agriculture, [S. l.], v. 2, p. 27-43, 2009. 